\title{
Porous materials via nanocasting procedures: innovative materials and learning about soft-matter organization
}

\author{
Sebastian Polarz $\dagger$ and Markus Antonietti \\ Max-Planck-Institute of Colloids and Interfaces, Department of Colloid Chemistry, Research Campus Golm, \\ Am Mühlenberg 2, D-14424 Golm, Germany. E-mail: pape\&mpikg-golm.mpg.de
}

Received (in Cambridge, UK) 12th June 2002, Accepted 15th August 2002

First published as an Advance Article on the web 24th September 2002

\begin{abstract}
Nanocasting, the 3D-transformation of self-assembled organic nanostructures into hollow inorganic replicas under preservation of fine structural details has recently turned out to be a versatile tool, both for the synthesis of porous media with new pore topology as well as for the characterization of the assembled structures themselves. This review gives a review on recent work describing the potential and restrictions of nanocasting using surfactants, polymers, colloids as well as supramolecular tectons as porogens.
\end{abstract}

\section{Introduction}

Porous matter, omnipresent in nature for structural and functional reasons, has just recently experienced a revival in chemistry. The reasons for that are threefold: substances with small pores exhibit inherently a large surface area, which is favourable for reactions at surfaces (as catalysis) or adsorption (chromatography and separation). In addition, people have learned that the properties of the wall material (between the pores) and the filling (in the pores) is very different from the corresponding bulk material, and changes in melting points, solvent polarities, as well as altered optical and electronic behavior are regularly found. A third rationale for the

Dr Polarz studied chemistry in Bielefeld/Germany and finished his diploma thesis in 1999 working with Prof. A. Müller in the field of supramolecular giant polyoxometalates. He then joined the Max-Planck Institute of Colloids and Interfaces where he finished his PhD 2001 under supervision of Prof. M. Antonietti. His work on nanocasting was rewarded with the Otto-Hahn medal by the Max-Planck society. Dr Polarz is currently working with Prof. G. A. Ozin at the University of Toronto/ Canada focusing on ordered mesoporous organosilica-, transition metal oxide-and photonic materials. His main interests are chemistry under confined conditions and mesoporous materials.

Markus Antonietti was educated in physical chemistry in Mainz but afterwards became rapidly addicted by the joy of sculpturing chemical nanostructures. He is director of the Colloid Chemistry Department of the MPI of Colloids and Interfaces since 1993. His research interests are to desperately herd a flock of techniques in the field of nanochemistry, such as the self assembly of polymeric tectons, the making of stable nanodroplets and confined reactions, nanocasting and-coating, or supramolecular complexes made by the ionic self-assembly route.

$\dagger$ Current address: University of Toronto, Lash Miller Chemical Laboratories, 80 St. George Street, Toronto, Ontario, M5S 3H6 Canada. morphosynthesis of porous systems is that sometimes one can learn from the pore formation process about the structure of the system in itself, as will be delineated below.

Porous materials should contain voids as a majority phase, either with random character (disordered pore systems) or with high regularity (ordered pore systems). A classification of pore systems is achieved by the pore diameter $D_{\mathrm{p}}{ }^{1,2}$ Pores below 2 $\mathrm{nm}$ are called micropores. Important materials of this class are for instance the well-known zeolites. ${ }^{3-6}$ Mesopores by definition are found in the range $2 \mathrm{~nm}<D_{\mathrm{p}}<50 \mathrm{~nm}$. The most prominent member of this class is the so-called MCM-41 introduced in 1992 by Beck, Kresge et al. $.7,8$ The preparation of MCM-41 had already been reported in 1971 by Chiola et al.(as delineated in ref. 9) but the extraordinary character of this material was not realized. Since 1992, numerous important achievements have been made by hundreds of groups worldwide, and it is therefore difficult to give a fair overview on these activities. Some excellent review articles ${ }^{10-13}$ about mesoporous materials and their applications ${ }^{14-16}$ can be found. Finally, pores exceeding $50 \mathrm{~nm}$ are called macropores.

The classical MCM synthesis is a route which we call 'synergistic precipitation', i.e. a non-organized surfactant solution is coprecipitated with a condensing sol-gel mixture, and the fine structural details and pore structure develop throughout the condensation process. Here, usually powder like materials are obtained, and the resulting pore size is highly reproducible, but barely predictable on the basis of the starting solution. Another approach which allows rational prediction of the pore architecture was introduced by Attard, Göltner et al. and was termed 'true lyotropic liquid crystal approach' $17-20$ or 'nanocasting'. Here, one starts from a high concentration surfactant phase, and the liquid continuous phase is just solidified by some chemical reaction, either a sol-gel reaction or a reductive coupling. That way, not only porous silica, but also porous metals were made. ${ }^{17}$ Scheme 1 depicts the general procedure of nanocasting.

Already in the early work, it was shown that this technique offered the possibility of making a 1:1 imprint or negative copy of the organic template. X-ray measurements performed throughout the process showed that the solidified hybrid preserved all structural features throughout the solidification of the matrix, and even the calcined or hollowed replica possessed the same structure, only slightly shrunken. ${ }^{17-19}$ In contrast to the cooperative assembly of the MCM process, size, shape and connectivity of the pore is solely determined by the size and shape of the template that pre-exists in solution prior to formation of the solid network (see Scheme 1). The term 'nanocasting' comes from the fact that this process is analogous to classical bronze casting (the lost wax technique), however on the nanometer scale. The technique allows in principle a creation of pores and porous systems by rational design with respect to: 


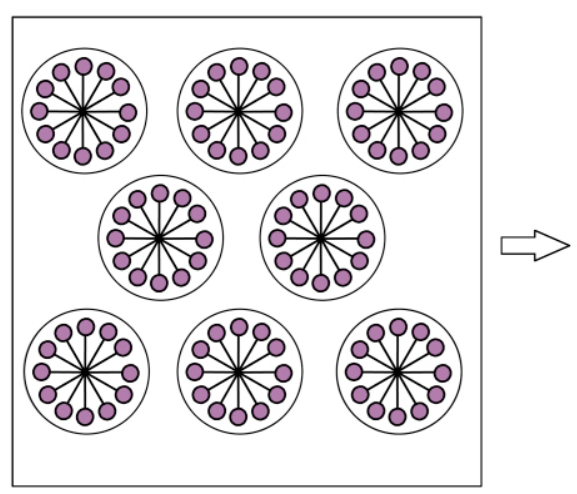

Sol-gel
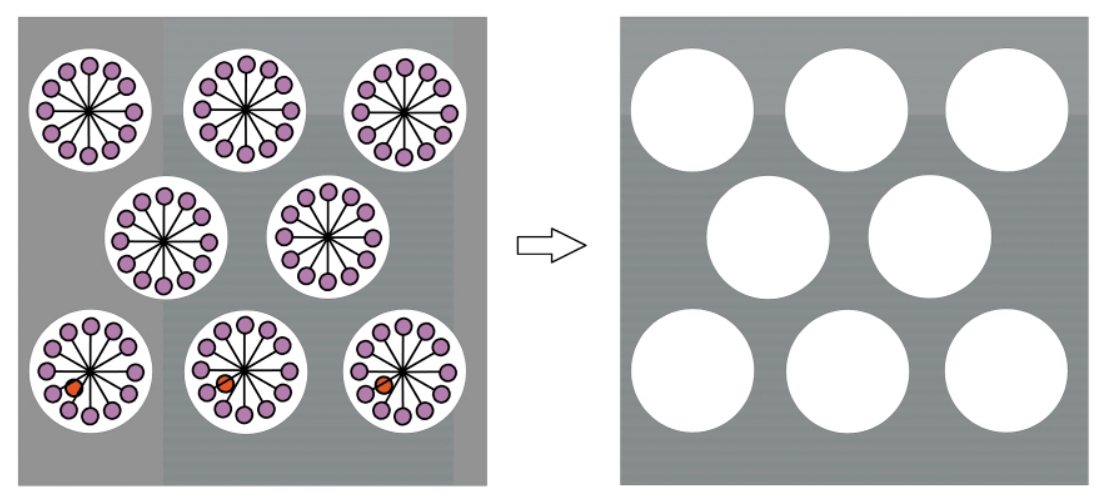

Removal of the template

Scheme 1 Schematic representation of the nanocasting concept. The nanocasting involves two main steps, (a) provision of a suitable template, and (b) the casting step. Units of different dimensions and different aggregation levels can act as templates, such as molecules, aggregated structures of amphiphiles, colloids or colloidal crystals. In the casting step (b) this template unit has to be surrounded by a network-precursor small enough to be able to follow the details of the template, and its cross-linking has to preserve the original structure. The final pores are obtained by removal of the template, e.g. by calcination.

- pore size

- pore morphology

- pore distribution in 3D space

- properties and composition of the network material, and

- control over the macroscopic shape of the material.

These are the most important characteristics of a porous systems you can imagine, and this is the promise of nanocasting.

\section{Nanocasting and its restrictions}

Nanocasting acts on different length-scales via a number of templates. Both single molecular or single colloid templates as well as a variety of self-assembling tectons might be suited for the nanocasting process. However, it is important for the interface of the structure to be compatible with both the liquid precursor phase as well as with the final solidified replica, else the enormous interfaces involved (up to $1000 \mathrm{~m}^{2} \mathrm{~g}^{-1}$ ) will be energetically unfavourable, cause demixing and subsequent Ostwald-ripening, i.e. the molecular casting is not successful, and ill-defined and/or macroscopic replicas of this state are obtained.

This is why most work indeed is done on porous sol-gel silica, ${ }^{21}$ which is easy to control and the final product, amorphous $\mathrm{SiO}_{2}$, is easy to address and able to adopt even the smallest structures. The coupling between the silica and the organic template (in other words: the lowering of the interface energy close to zero) is done in a variety of fashions. The possibility of transcription of single molecules to pores has already been explored since 1949 with the work of Dikey. ${ }^{22}$

Originally, in MCM-materials cationic surfactant systems together with silica-sols under basic conditions were employed. It has in the meantime been accepted that the negatively charged silica precursors (silicic acid and oligomers) interact with the cationic head-groups of the surfactants. ${ }^{23-25}$ Another standard compatibilisation is via non-ionic alkyl-PEO amphiphiles, first demonstrated by Pinnavaia et al. ${ }^{26-28}$ Here it is the formation of hydrogen bridges between the silicic acid and the ether oxygens of the PEO chain which stabilizes the interface, and the gelation of the $\mathrm{SiO}_{2}$ network is preferentially done close to $\mathrm{pH}=2$ which is the isoelectric point of silicic acid. Beside that, polyhydroxylated species such as mono- and disaccharides 29,30 were also employed, all binding via $\mathrm{H}$-bridges to the silica matrix. Here also, acidic $\mathrm{pH}$ conditions are favourable. In some cases, nanocasting is also done with polysulfonic acids, 31 alkylsulfates and sulfate stabilized latexes. ${ }^{32}$ Since these condensation reactions are also performed under acidic conditions, presumably here also H-bridges mediate between the phases.

When either the interface energy (thermodynamic factor) or the network formation process (kinetic factor) cannot be efficiently controlled, one encounters the limits of nanocasting. The latter case is given for many transition metal oxides or other networks than silica. The network precursors are much more reactive and crystallisation of the phase becomes important. It is only recently that mesoporous materials of this kind have been developed. ${ }^{33,34}$ In the meantime, electrochemical reduction of metals to form porous electrodes is also possible with non-ionic surfactants. ${ }^{17,35}$ On a higher length-scale of some micrometers these factors are not so dominant and the transcription of some polymer gels into porous systems ${ }^{36,37}$ has been achieved, a process which has been also described as nano-coating. ${ }^{38}$

Extension of the nanocasting technique to other porous matrix materials is therefore more complicated. Application of template techniques to other inorganic materials relevant to material science such as ceria, titania and zirconia is-for instance-described in the excellent work of Sanchez et al., ${ }^{39-41}$ but is treated in more detail in the present review.

Due to thermodynamic reasons, it is usually not possible to create porous polymers that way, ${ }^{42}$ except in one successful case where block copolymer micelles were used as templates and polymer-polymer miscibility was sufficient. ${ }^{43}$

\section{Analysis of porous materials: problems and developments}

Generation of porous materials with ordered nanostructure is enevitably coupled to the characterization of those materials. The 'secrets' of porous materials cannot be revealed by using only one analytical technique. A standard combination of techniques includes:

(i) Transmission electron microscopy (TEM).

(ii) Gas sorption analysis.

(iii) Small angle X-ray analysis (SAXS).

To lead the reader through a typical argumentation, a typical porous material obtained by nanocasting with a non-ionic alkylPEO amphiphile (Brij-surfactant) first prepared by Pinnavaia et $a l .^{26-28,44}$ and its analysis is shown in Fig. 1.

The SAXS-pattern shows (Fig. 1a) only one clear scattering maximum at $s=0.20 \mathrm{~nm}^{-1}$ and a broad oscillation at $s=0.40$ $\mathrm{nm}^{-1}$. Although such a scattering pattern is not suitable for 

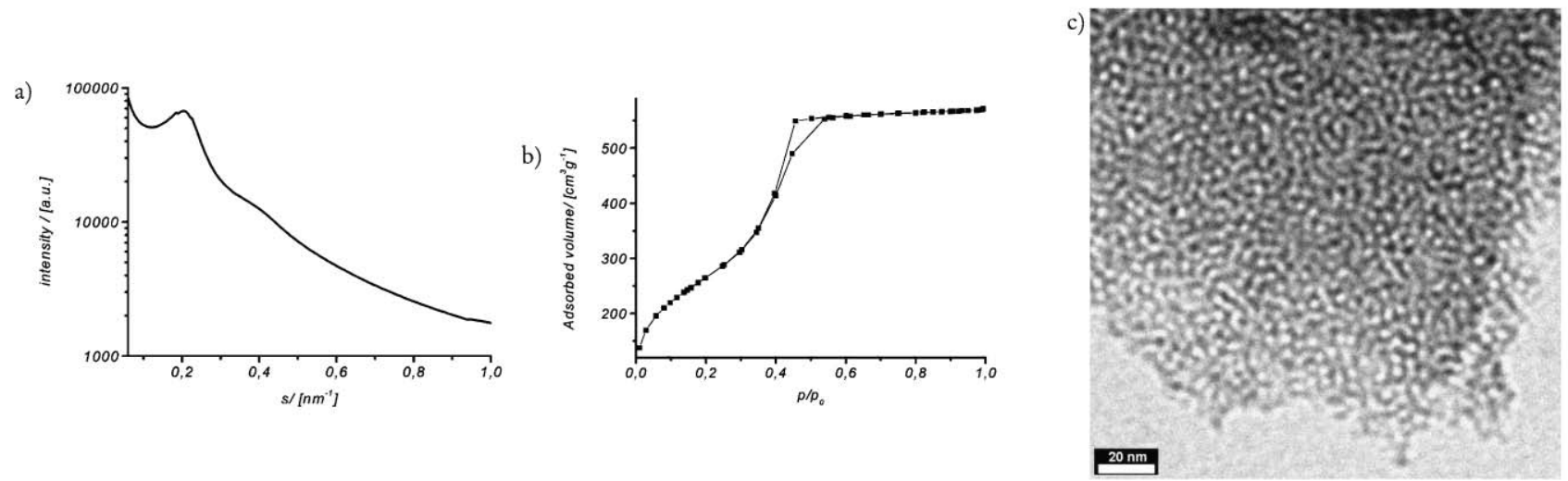

Fig. 1 Analytic details for a porous material based on a lyotropic liquid crystal of classical amphiphiles $\left(\mathrm{C}_{18} \mathrm{EO}_{20}\right)$ as the template: (a) $\mathrm{SAXS}$ curve, (b) $\mathrm{N}_{2}$ isotherm, and (c) TEM image.

classical crystallographic methods where the scattering is given by a superposition of the structure-factors and form-factors, one is able to determine a $d$-spacing of $\approx 5 \mathrm{~nm}$, however only of locally ordered materials. TEM on the other hand, presents a material that looks quite defined. Clearly defined and monodisperse pores with moderate mutual order are found in the silica network, and one would characterise this materials as 'worm-hole' type. The gas sorption analysis (Fig. 1b) shows a feature that is typical for mesoporous materials (capillary condensation step and hysteresis pattern). ${ }^{1,2,45,46}$ However, the large value for the adsorbed volume at low pressures and the high slope indicate that pores in the micropore region are present as well, left unseen in electron microscopy or in the simple interpretation of the X-ray data. Total surface areas calculated by the BET algorithm can be as high as $1000 \mathrm{~m}^{2} \mathrm{~g}^{-1}$ while a mesopore system is capable of providing just $200-300$ $\mathrm{m}^{2} \mathrm{~g}^{-1}$ surface area, which means the surface area is dominated by micropores (70-80\%), and adsorption does not correlate to the symmetry of the mesopores, which explains a number of the NMR observations on so-called mesoporous silica. ${ }^{47,48}$ It is obvious from these comments that no single analytic techniques reveals all the characteristics of a porous sample.

Further techniques have to be employed in order to ensure homogeneity of a material. It is pointed out that homogeneity is not equal to order. Many ordered materials might be more inhomogeneous than the porous silica derived by nanocasting techniques as depicted in Fig. 1. In the case of MCM-41, powders are obtained and the yield of hexagonally ordered grains is lower than $100 \%$ in most cases. The interstices between the micrometer large silica-grains create a separate porosity and the external surface area of the grains is not negligible in comparison to the internal surface area. Materials of the SBA-type (e.g. SBA-15) ${ }^{49}$ although appearing to be highly ordered, are not ordered through and through (see Fig. 2) in most cases. The materials shows less ordered 'worm-type' phases besides the hexagonal channels. Even the transitions between the two states can be depicted (see Fig. 2 b). The areas of defined porosity might as well be separated by macroporous domains as detailed SEM-analyses reveals.

Such macroscopic or grain heterogeneities just occur for powder routes, not for nanocasting which gives materials in form of monoliths. Materials obtained by nanocasting are therefore homogenous even when possibly not highly ordered.

The presented techniques TEM, SAXS, and sorption are still under development and some major progress has been made recently. Sakamoto et al. presented a method to obtain 3-D imaging of pores in a mesoporous system. ${ }^{50}$ These authors use electron diffraction in a high resolution electron microscope preserving phase information of the scattered electrons. The obtained 2-dimensional scattering patterns equipped with this phase information allows the calculation of the 3-D spatial structure of the material by Fourier-transformation.

Smarsly et al. were able to significantly extend the available quantitative information from $\mathrm{X}$-ray scattering curves of porous two-phase systems by transformation of the data in relevant real-space coordinates into topological invariants instead of using a classical crystallographic approach. ${ }^{51-53}$ This method allows the determination of the so-called chord-length distribution (CLD) function, which is an accurate measure for pore size, pore shape, and in case of bimodalities, also pore size distribution. The CLD extrapolated to vanishing lengths also gives a measure for the 'angularity' of the wall, i.e. if the walls are flat and homogeneous or show slits, steps, and crazes.
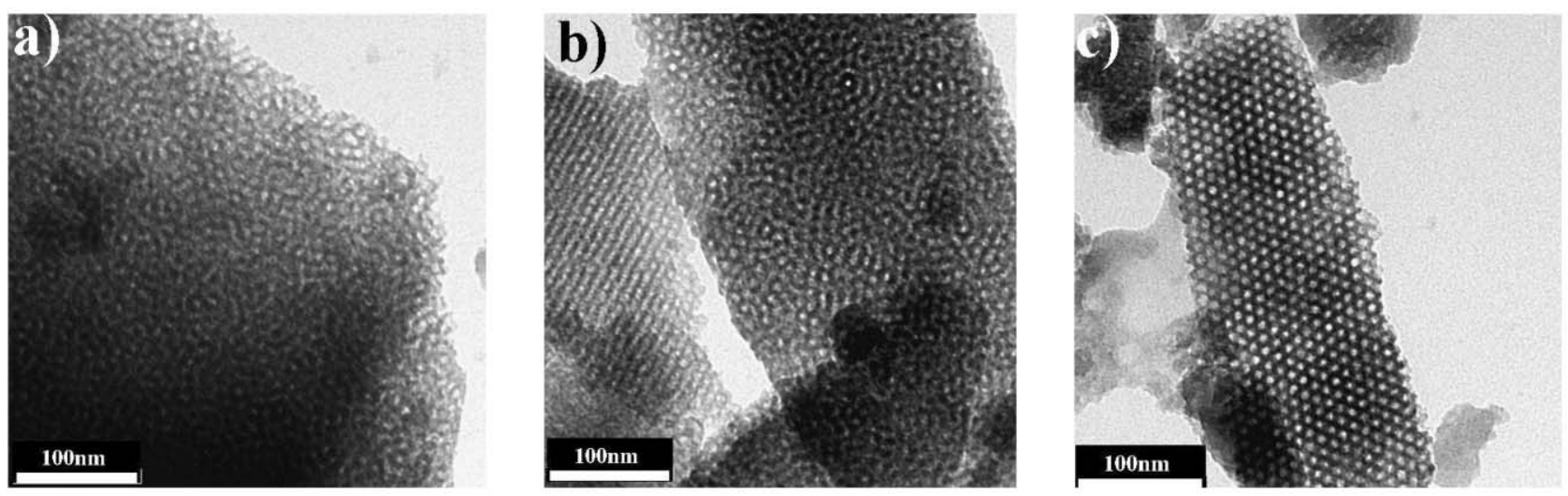

Fig. 2 TEM images of three spots of the same batch of a SBA-15 type porous material: (a) 'worm-type' pore morphology, (b) transition region 'worm-type' to hexagonal, and (c) hexagonal symmetry. 
Fig. 3 show the application of the CLD approach to the characterization of a silica templated with non-ionic surfactants

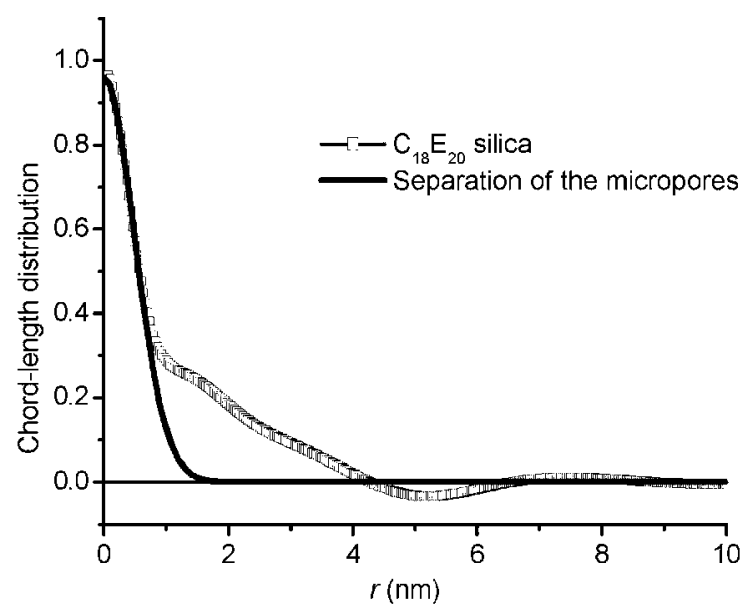

Fig. 3 CLD-function for $\mathrm{C}_{18} \mathrm{E}_{20}$-silica, as calculated from SAXS data, and the separation of the micropores. The corresponding scattering curve was shown in Fig. 1. The analysis was performed by Dr B. Smarsly.

where-as discussed above-additional micropores had to be postulated. Whereas nothing peculiar is seen in the bare scattering data, the corresponding CLD (Fig. 3) clearly reveals a bimodal pore size distribution with the well known mesopores with a pore size of about $4 \mathrm{~nm}$ (first intercept with the $\mathrm{X}$-axis), a regular pore to pore distance of $6.5 \mathrm{~nm}$ (second intercept), the difference corresponding to the wall thickness. However, the major peak is determined by a majority fraction of micropores below $1.5 \mathrm{~nm}$ in size. These micropores, for the first time clearly identified and characterized, contribute to $70-80 \%$ of the surface area and are presumably_-due to their size and shapethe leftovers of the PEO chains formerly embedded in the wall material. It is important to note that for these materials due to the similar size of meso- and micropores (separated just by $3 \mathrm{~nm}$ ) a quantitative analysis would not be possible with gas sorption techniques. The method developed by Smarsly et al. is applicable to all kinds of materials, even disordered ones like activated carbon blacks.

There is much activity in the field of sorption analysis of porous materials which is beyond the scope of this manuscript. However, one innovation that is relevant for this paper is the introduction of density functional theory to sorption analysis. 54,55

\section{Materials obtained via nanocasting}

\section{Classical amphiphiles as templates ${ }^{56}$}

The first amphiphiles that were employed as templates for the preparation of mesoporous materials were cationic surfactants. ${ }^{7,8}$ It was also discovered during this time that the pore size depends on the length of the alkyl chain in the surfactant. Soon, the first materials using neutral templates as amines or Brijsurfactants $26-28,44,57$ were prepared. The pore size that could be achieved using these templates was, due to the chosen precipitation route, more or less an empirical parameter. It was Attard and Göltner ${ }^{18}$ who showed that in the limit of nanocasting there is indeed a direct relation between pore size and pore topology to the aggregate geometry of the original phase. Recently, a very systematic approach and description was published how the amphiphile structure is related to the mesopore shape, performed with amphiphiles which have a PEO-block as the hydrophilic part. 56

The most naive picture, which rapidly turned out to be wrong, is to assume that the pore is essentially of the size of the surfactant micelle, that is both hydrophilic and hydrophobic part separate from the silica and form-after removal-the pore (see Fig. 4a). If the silica binds strongly to the PEO-tails, the PEO would create fine micropores (which indeed are found), and the mesopore would possess the size of the hydrophobic domain (see Fig. 4b).
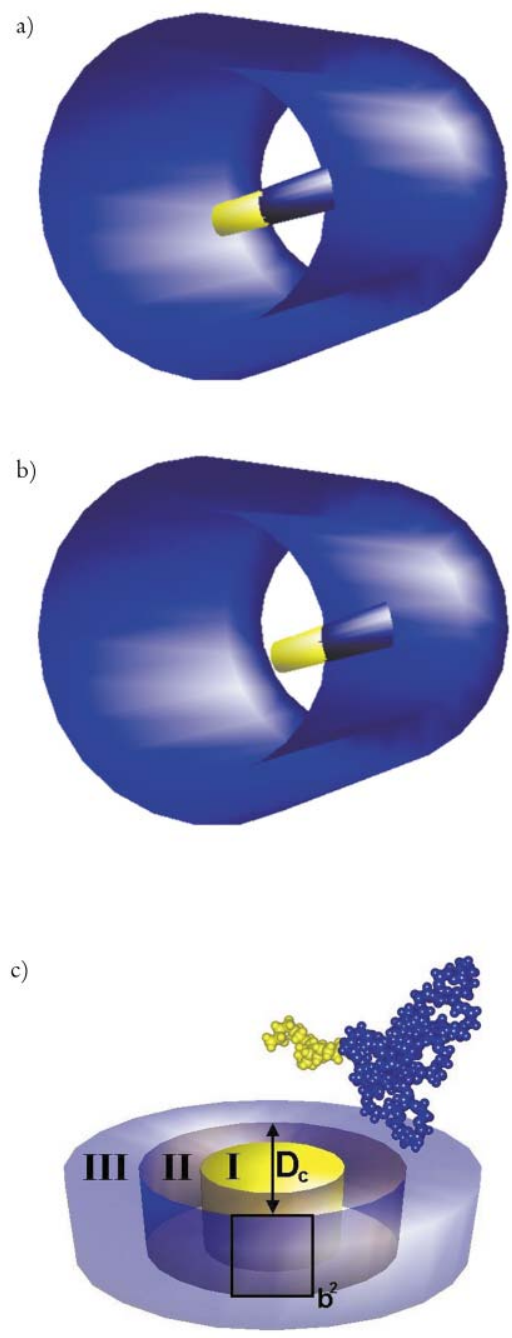

Fig. 4 Schematic representation of the three mind experiments on how a mesopore gets constructed: (a) the 'one-phase model', where the whole surfactant volume contributes to the mesopore; (b) the 'two-phase model', where just the hydrophobic part forms the mesopore, the hydrophilic part anchors to and is embedded in the silica wall; and (c) the 'three-phase model' where parts of the hydrophilic tails contribute to the mesopore volume by formation of depleted dense shell (II) around the hydrophobic core (I), the other parts of the PEO-chains are mixed with the silica phase (III) and contribute later to the micropores. (c) Shows for simplification a slice from a cylindrical aggregate of amphiphilic molecules. One of these molecules is also shown with the PEO-block (blue) and the hydrophobic alkyl-block (yellow).

It turned out that a so-called 'three-phase' model shown in Fig. $4 \mathrm{c}$ is correct, i.e. parts of the PEO chains contribute to the core and are associated with the mesopore volume, whereas the outer parts of the corona are indeed embedded in the silica and create micropores after removal of the template. Details of the data evaluation will be rediscussed in the chapter on analysis below.

With this model, it was possible to explain the pore sizes generated from nonionic Brij-surfactants in dependence of the full accessible range of hydrophobic $\left(\mathrm{C}_{8-18}\right)$ and hydrophilic $\left(\mathrm{C}_{4-30}\right)$ block lengths, graphically presented in Fig. 5 .

It is seen that the pore size depends on both block sizes, i.e. the dependence on the hydrophobic block is stronger $\left(D_{\mathrm{c}} \propto\right.$ 


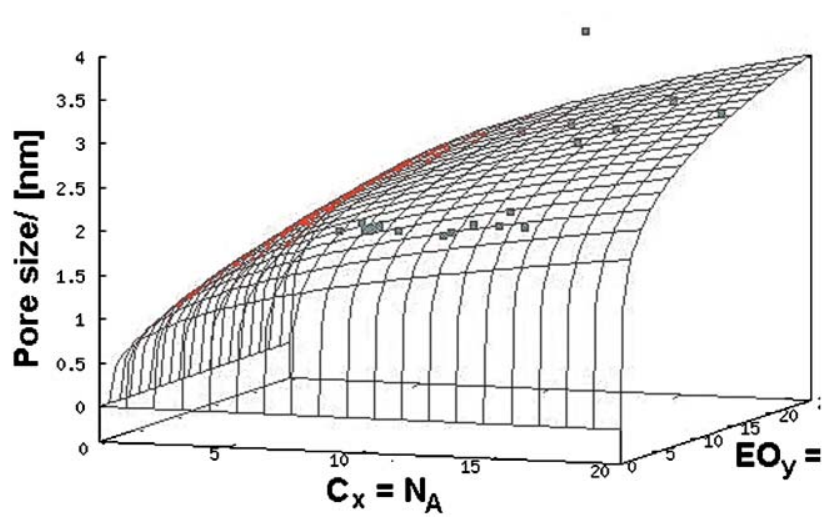

Fig. 5 Dependence of the pore size on the length (in monomer units) of the hydrophilic and the hydrophobic block, illustrating the fine adjustability of the pore size.

$\left.N_{\mathrm{A}}{ }^{0.4}\right)$ but the pore diameter also depends on the length of the hydrophilic PEO block $\left(D_{\mathrm{c}} \propto N_{\mathrm{B}}{ }^{0.25}\right)$. These relationships are only consistently explained by the three-phase model, as mathematically delineated in ref. 56 Using quantitative small angle X-ray scattering, it was shown that from $30-80 \%$ of the total amount of EO can be located in the aqueous domain of the lyotropic liquid crystals and later within the silica walls (creating micropores), whereas $70-20 \%$ of EO contribute to the volume of the mesopore. Just in the case of a relatively dominant (large) hydrophobic block practically all the EO is needed to stabilise the interface. Then, the high dispersion of $\mathrm{PEO}$ in the aqueous silica phase leads to high microporosity, comparable to a classical micellar (two-phase) model. These findings underline that at interfaces there is a gradual change of interface energy gradient and not a volatile transition. There is a portion of PEO adopting hydrophobic properties and a portion adopting hydrophilic properties.

Beside understanding the structure of micelles, such scaling relationships also allow the adjustment to a distinct pore size with Angstrom precision. It was shown too ${ }^{56}$ that the primary scaling law can also be used to create mixing laws, i.e. instead of using just one template molecule, a mixture of chemically equal but differently sized templates in correct ratio might be employed to result in a specific pore size. For Brij-surfactant it was shown that any pore size in between the borders defined by the parent amphiphiles can be realized simply by mixing the amphiphiles in the template.

\section{Amphiphilic block copolymers as templates}

Amphiphilic block copolymers act similarly as non-ionic surfactants, but are much larger and more stable templates which allow wider variation of chemistry and casting conditions. Here, the range of accessible pore sizes is extended to 5 $\mathrm{nm}<D_{\mathrm{P}}<100 \mathrm{~nm}$, and a variety of pore connectivities have been made. Because of size and the higher stability, one can directly depict the quality and precision of the nanocasting process.

Hentze et al. could show this by fixing a lyotropic phase of a poly(butadiene)-poly(ethylene oxide) PB-PEO block-copolymer by $\gamma$-radiation and comparison with the silica nanocast of a non radiation-treated PB-PEO liquid crystal phase as the template (see Fig. 6)..$^{58}$

The solid silica imprint had the inverted structure of the organic template, but the template structure was not affected by the casting process itself, as seen by the direct relationship. Because of these advantages, a whole variety of amphiphilic block copolymers has been used. Beside the first used non-ionic structures with PEO chains to mediate silica compatibil- a)

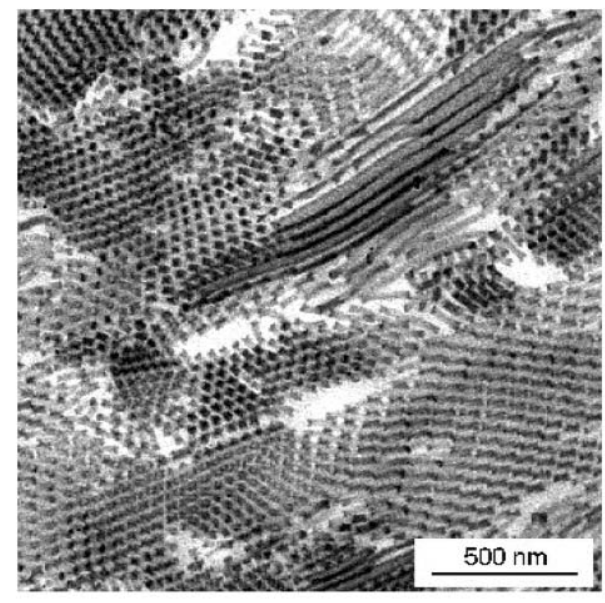

b)

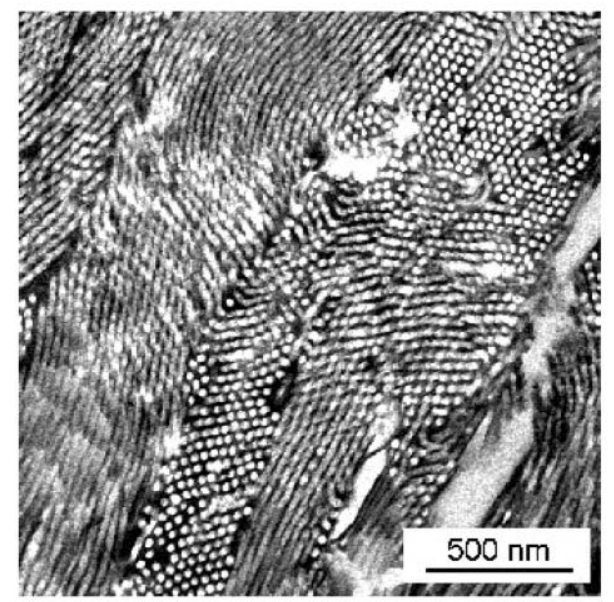

Fig. 6 TEM images of a lyotropic phase and the resulting mesoporous materials obtained by nanocasting. (a) Shows a lyotropic phase of a PBPEO block-copolymer structurally fixed by cross linking of the double bonds with $\gamma$-radiation. It can be seen that the pore system ('inverse matter') has exactly the size and shape expected under the assumption of a $1: 1$ transformation process. ${ }^{58}$ The term nanocasting is justified.

ity, ${ }^{19,59-61}$ cationic and anionic polyelectrolyte blocks have also been employed. ${ }^{31}$

The first reported systems have been poly(styrene)-PEO block-copolymers of low molecular weight. A polymer with $M_{\mathrm{w}}$ $=1000 \mathrm{~g} \mathrm{~mol}^{-1}$ in each of its block segments (named SE1010) gives a pore size of $4.8 \mathrm{~nm}$ while a larger block-copolymer with $M_{\mathrm{w}}=3000 \mathrm{~g} \mathrm{~mol}^{-1}(\mathrm{SE} 3030)$ results in $9.5 \mathrm{~nm}$ pores, possessing some distorted hexagonal structure with many branches. ${ }^{19}$ A representative structure is shown in Fig. 7.

In the case of the PEO-b-PB block copolymers, other pore morphologies can also be made. ${ }^{62-64}$ Fig. 8 depicts two unconventional phases and their nanocasting replicas, the bicontinuous sponge-like phase (Fig. 8a,b) and the branched lamellar phase (Fig. 8c,d), which can be adjusted for certain block copolymer compositions and template concentrations.

Beside that, isolated cylindrical micelles, hexagonal phases as well as extended lamellar and vesicular phases have been cast, where lamellar phases without supporting curvature show structural collapse.

\section{Single polymers and molecules as templates}

Single molecules can be used as porogens as well. Under nanocasting conditions the pore reflects the architecture of the template molecule. It was pointed out already in 1949 by Dickey that porous silica materials prepared in the presence of methylorange specifically adsorb dyes of the same architecture. ${ }^{22}$ The approach of imprinting molecules (molecular imprinting) on all 


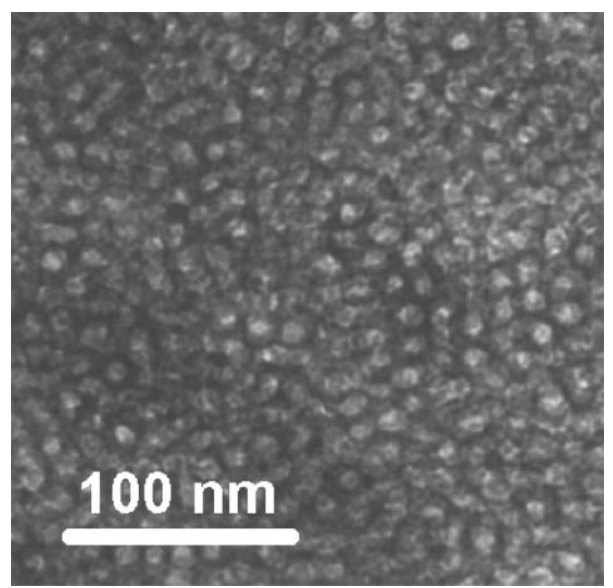

Fig. 7 TEM image of SE1010-silica.

sorts of networks is now widely in use also for polymeric materials. ${ }^{65,66}$ Single polymers can also be employed as a template for porous silica and under nanocasting conditions the pore morphology is again directly related to the polymer architecture ${ }^{67}$ However, the polymer is not removed in most cases but the goal is to obtain silica-organic hybrid materials 68 with new properties. A large variety of polymers like poly(ethylene oxide), poly(methyl methacrylate), ${ }^{6}$ poly(vinyl alcohols), ${ }^{70}$ poly(vinyl acetate), ${ }^{71}$ and others were used for this purpose. Still the requirement that the template has to be compatible with the sol-gel process and the final silica obviously remains.

a)

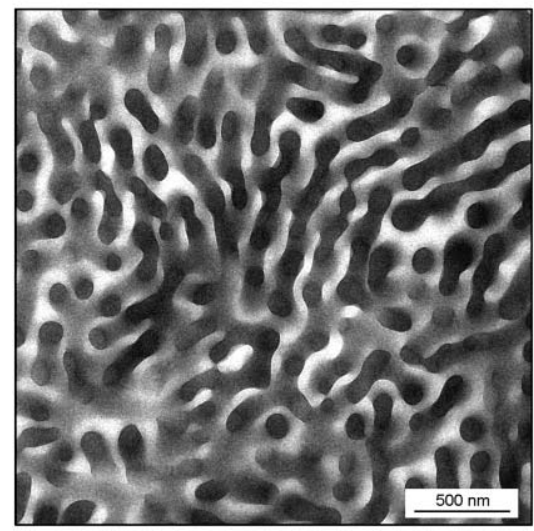

c)

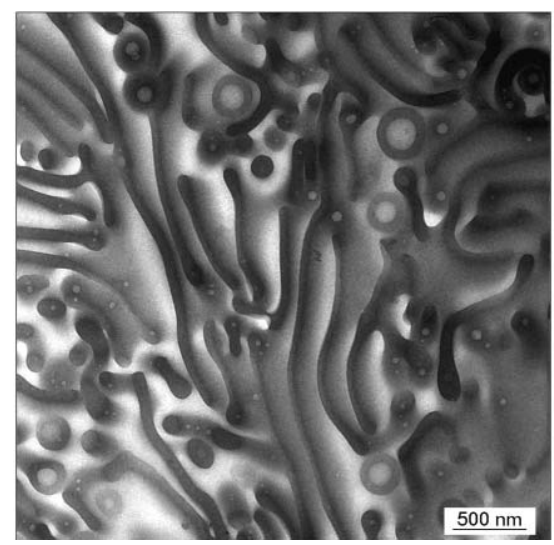

Recently, also, dendrimers have been used for the preparation of porous materials. ${ }^{72}$

\section{Latex particles and microgels for templating applications}

To increase the pore size to still larger sizes, but also to choose industrially relevant templates with a very low price, polymer dispersions or latexes have been employed. ${ }^{73}$

For catalytic or sorption applications, mutual pore order is not required, and the latex can be cast as it is, resulting in spherical pores with addressable pore sizes between $30 \mathrm{~nm}$ and $500 \mathrm{~nm}$. Such a typical system is shown in Fig. 9a. Since latexes are rigid templates which do not interfere with the self-assembly of surfactants, it is possible to employ both templates at the same time, thus making the walls between the latex pores porous in themselves (a network with bimodal porosity), as shown in Fig. $9 b$.

Such networks with bimodal porosity have a number of advantages. On the one hand, they combine the improved permeation properties of a large pore system with the high surface area of a small pore system. On the other, the absolute porosity can easily be increased beyond 80 vol\% without endangering the structural integrity of the material, as the pores and their percolation thresholds are distributed along two length scales.

A variation of this technique is to use polyelectrolyte microgels as templates. These microgels are as latexes on the outside, but water swollen on the inside, thus allowing the transport of functionalities such as metal nanoparticles into the silica framework. ${ }^{74}$ b)

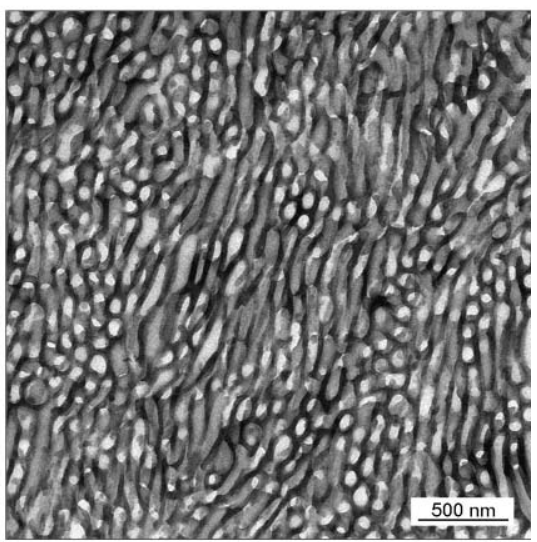

d)

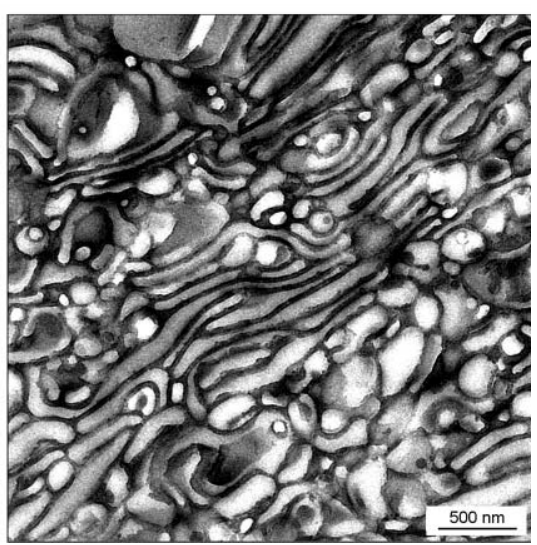

Fig. 8 TEM pictures of cross-linked original mesophases and their silica replicas: a) bicontinuous sponge-like phase and b) replica; c) branched lamellar phase and d) its replica. 


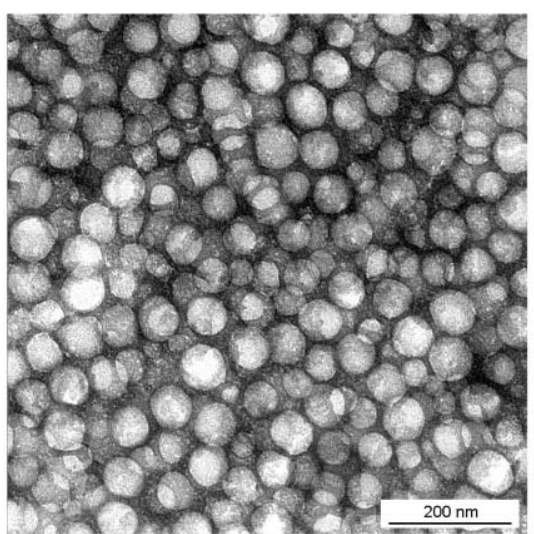

b)

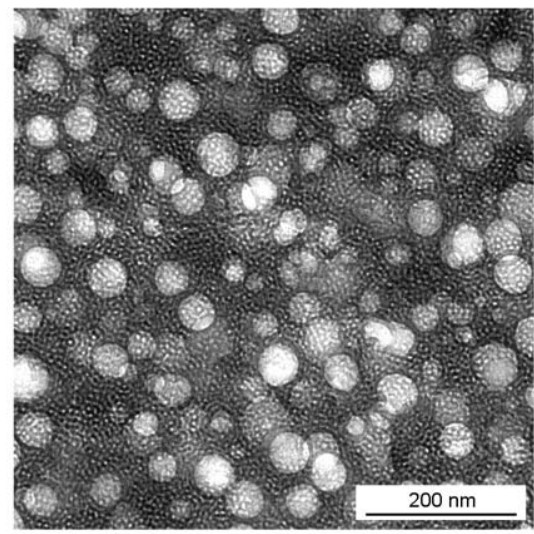

Fig. 9 Porous silica materials obtained by nanocasting of polymer dispersions. a) Purely macroporous material obtained from nanocasting of a 60 nm polymer latex. b) Silica with a bimodal pore size distribution by simultaneous nanocasting of a latex plus a coexisting SE 1010 phase. This system exhibits both 60 $\mathrm{nm}$ and $6 \mathrm{~nm}$ pores thus increasing the absolute porosity under preservation of structural integrity.

In the case of an ordered polymer latex or a colloidal crystal, the pore system also is highly ordered, and porous materials with interesting optical materials, such as photonic band gaps are obtained. ${ }^{75-77}$ Since this topic is currently exploding and relies on reviewing in itself, we will only illustrate the quality of the resulting structures in Fig. 10.

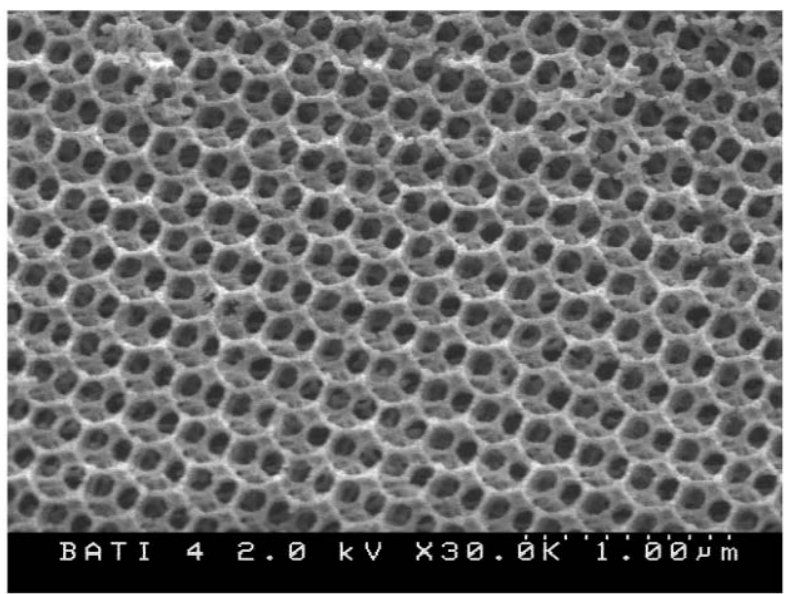

Fig. $10 \mathrm{SEM}$ picture of a regular, 'photonic band gap'- $\mathrm{BaTiO}_{3}$ material made with a colloidal latex crystal as a template. We thank Ivana Soten/ Toronto for the picture.

Nanocasting of sphere assemblies has become one of the most powerful tools in modern materials science for the production of opals and photonic materials. ${ }^{77}$

\section{Inorganic clusters or polyoxometalates as template systems}

Not only organic molecules, but also inorganic templates can be used for nanocasting, as long as it is possible to promote secondary binding events between the surfaces of the two structures. A wonderful system for this are giant polyoxometalates pioneered by Müller et al. ${ }^{78,79}$ Mainly, these systems contain single-species ring-shaped and sphere-shaped polyoxomolybdate clusters in the nanometer region which are highly charged and can therefore be Coulomb-coupled. It was shown that these clusters indeed can be homogeneously embedded in a silica matrix, thus resulting in interesting polyoxometalate-silica hybrid materials ${ }^{80}$ with the potential of photocatalysis. ${ }^{81}$ Since the template is inorganic, removal of the structure given pattern is not easily possible. On the contrary, it was shown that a number of redox reactions can be performed with the molybdenum centers, keeping the number of metal atoms in every pore constant (even the side products cannot leave). This is a promising new aspect of chemistry in pores being part of the bigger concept of 'nanochemistry' 82,83 where new reactions are enabled by nanostructure confinements. Beside all material science aspects, these experiments also prove that the clusters are actually also present in solution (as monodisperse species) and not just reconstituted in the crystal, which was an open question for the employed 'dynamic-library approach'.

\section{Functionalization and application of porous materials made by nanocasting}

\section{Learning about soft-matter aggregation}

It became obvious on a number of occasions that due to the strict relationship between the template structure and the resulting pore system, nanocasting was more than just a synthetic tool. Vice versa, it can obviously be used to learn about the structure of the templates themselves. Since these are sometimes fragile equilibrium structures or aggregates they are not easy to depict by electron microscopy or X-ray experiments under natural conditions (insufficient contrast, beam damage and preparation artefacts).

Instead of investigating the soft-matter structure in its dispersion medium (most likely water) itself it is possible to examine the 'hardcopy' as the pore structure of a fixed stable material derived by nanocasting. This route (Scheme 2) potentially has several advantages in comparison with direct examination. The pores show high contrast and (for example for silica materials) are stable against most external conditions. This enables the application not only of analytical techniques such as electron microscopy or scattering techniques with their required 'extreme' conditions (high vacuum or high energy flux), but also the employment of methods which are usually not used for structural analysis, e.g. porosimetry ! Additionally, soft-matter structures are rather flexible and underlie thermally driven dynamics. Many analytical techniques just give an average picture of these structures while the solid network will fix 'snapshots' of some dynamically averaged situations as stationary pores.

It has been delineated that nanocasting already allows a quantitative model of micelle formation of non-ionic surfactants on the basis of X-ray and porosity data only. ${ }^{56}$ As compared to the otherwise applied neutron scattering, this is a real simplification. 


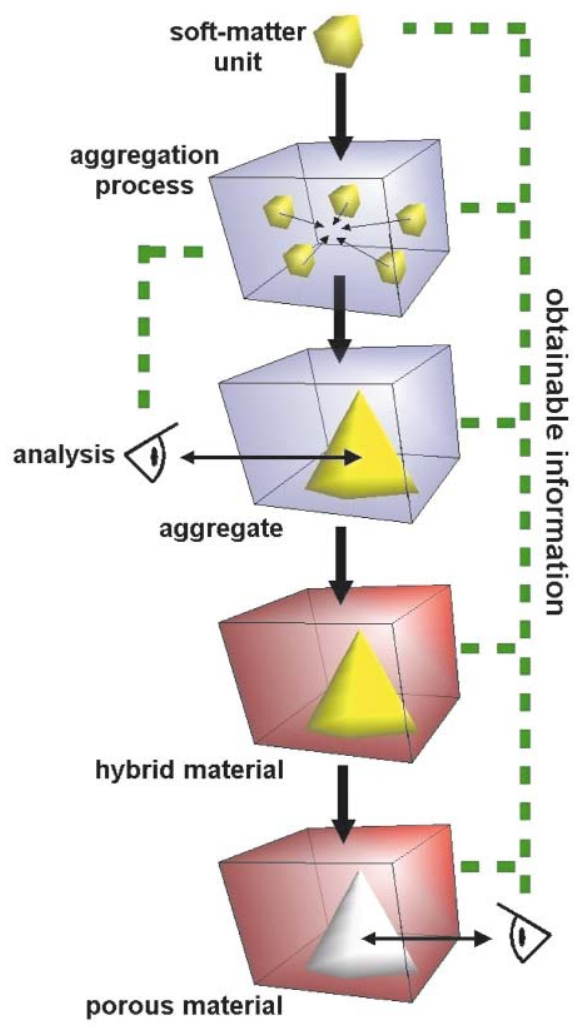

Scheme 2 Schematic representation about the mutual correlation between obtaining new porous materials and learning about soft-matter aggregation. When certain soft-matter units (amphiphiles) are put in water they start to aggregate. These aggregates are used as templates for the nanocasting process and lead to porous materials. When the pores are investigated details about the template structure, and in an optimal case even about the aggregation process, are obtained via analysis of the pore system.

A second model case for the serious outcome of this method to investigate soft-matter is given for cyclodextrins and their behaviour in water.

\section{Cyclodextrins as templates}

The question if the nanocasting principle can also be profitably extended to other supramolecular systems than micelles was answered by employing cyclodextrins as templates in the nanocasting process. ${ }^{84}$ Cyclodextrins are cyclic sugars containing $6(\alpha-), 7(\beta-)$, or $8(\gamma-C D)$ glucose units 1,4 -cyclically connected to a 'molecular barrel'. It is known from the literature 85 that these 'barrels' have an exterior which is covered by $\mathrm{OH}$-groups while the interior cavity is quite hydrophopic, characterized by $\mathrm{CH}_{2}$ groups. Due to the difficulties involved in the direct investigation (as already mentioned previously) the true solution structure of cyclodextrins in solution was still a matter of discussion 86,87 despite their high technical relevance.

Interestingly, when cyclodextrins (or their solutions in water respectively) are employed as templates, again 'worm-type' materials are obtained which are very similar to those obtained with classical amphiphiles (see Fig. 11).

Such a pore morphology is not possible for a molecularly dispersed system as one might have expected for the highly water-soluble cyclodextrins. Instead, the cyclodextrins have to form aggregates in aqueous solution which are depicted by the nanocasting process! The pore diameter of the materials, which are due to the nanocasting process obtained as monoliths or thin films, is directly related to the diameter of the single CD-units. For $\alpha$-HPCD (a hydroxypropylated $\alpha$-CD molecule) as a template $1.4 \mathrm{~nm}$ pores are obtained, while employment of $\gamma$ HPCD leads to $1.8 \mathrm{~nm}$ pores. This direct correlation is an important indication that the resulting pore system is due to the

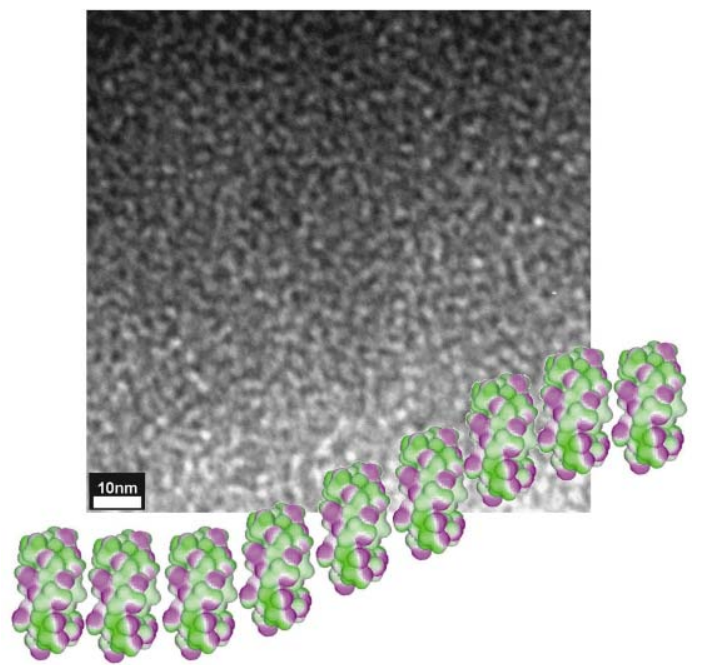

Fig. 11 TEM image of a representative CD-based silica demonstrating the 'worm-type' architecture of the pores and a schematic image of the CDalignment indicating the template structure.

assembled structure of the CDs and not an artefact. The difference between the hydrophilic exterior and the hydrophobic interior of the CD-molecule could be the driving force for this assembly.

For the quantification of the degree order and pore correlation, SAXS is a much more appropriate technique (Fig. 12). It turned out that-supporting the above given aggregation model-hydrophobic loading of cyclodextrins improves order and lining up of the cyclodextrins. The scattering pattern of the $\beta$-HPCD-silica confirms the conclusions drawn from the TEM images. The curves decay strongly and just a small shoulder at $s \approx 0.15 \mathrm{~nm}^{-1}$ can be observed. The scattering curve of the $\beta$ MCD-Xylene-silica exhibits a clear maximum at $s=0.12$ $\mathrm{nm}^{-1}$ which indicates mutual packing of the pores and higher order in the material.

The CLD evaluation of the same data reveals (Fig. 12b) that cyclodextrins as templates create just one type of pores. The size of the pores is exactly given by the diameter of the cyclodextrin. Additionally, the downturn of the CLD for $r \rightarrow 0$ indicated the materials are free of additional micropores, a feature that distinguishes these kind of materials from most porous compounds derived by classical amphiphiles (see sections above). The low value for $g(0)$ also reveals ${ }^{84}$ that the pore walls are rather smooth and free of edges.

It is worth mentioning that loading of the cyclodextrins with organometallic precursor molecules gives the opportunity for the in situ functionalization of the resulting porous oxides, ${ }^{88}$ as will be discussed below.

Beside cyclodextrins, pseudo-rotaxanes also can be templated. ${ }^{89}$ Cyclodextrins can be threaded onto different polyethers, depending on the ring size, and the resulting string-ofpearl morphologies were depicted by nanocasting. Here, an interesting rod-to-bundle transition occurred dependent on the $\mathrm{pH}$-value, which is in accordance with the Harada model: the threaded pseudorotaxanes show some type of nematic aggregation towards larger bundles. This transition could be characterized by analysing the resulting pore size distribution with BET and SAXS analysis. ${ }^{89}$

\section{Other investigations using nanocasting}

Nanocasting was additionally employed to characterize the nanoscopic assembly structure of semiconcentrated solutions of polymeric thickeners in presence of surfactants by X-ray analysis and porosity, otherwise a practically irresolvable problem. 90 


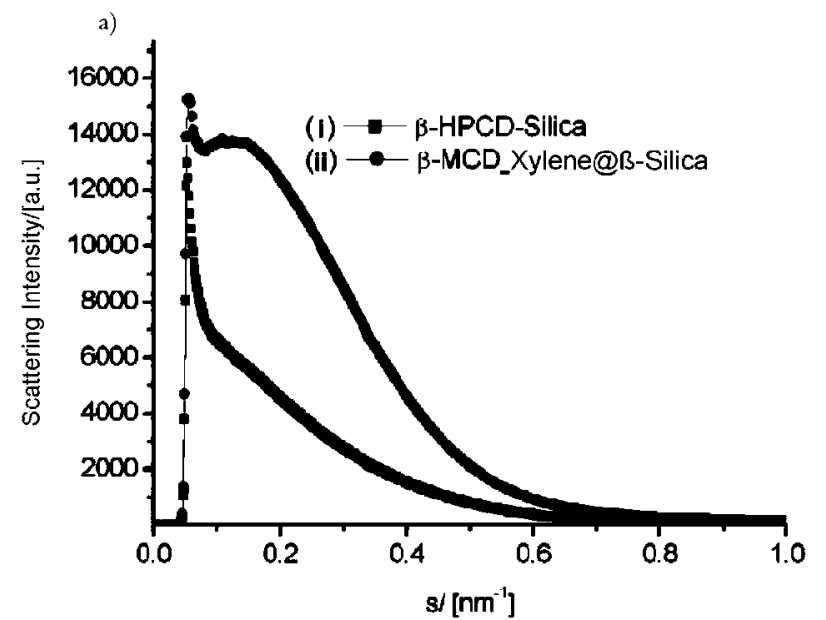

b)

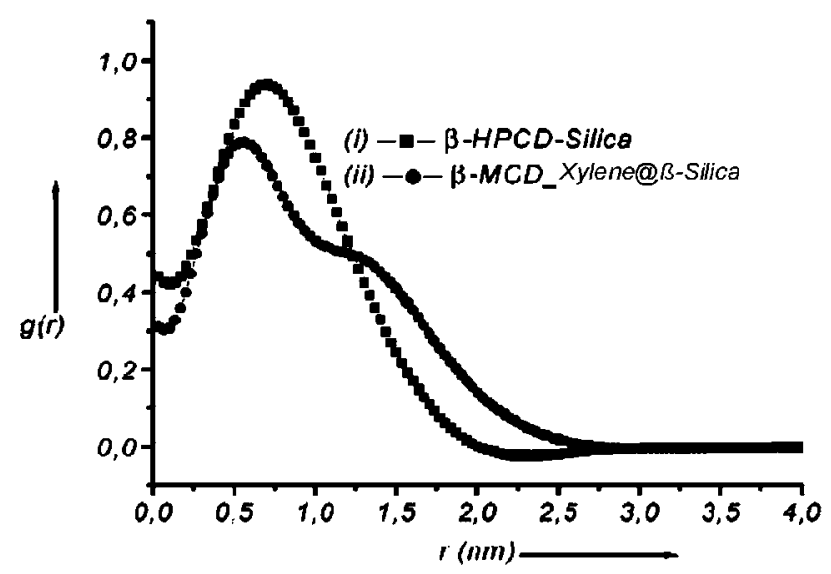

Fig. 12 SAXS diffractograms (a) of two CD-based porous materials. One was prepared using the hydrophilic $\beta$-HPCD (i) showing a rather disordered pore-system, the other one was prepared with xylene@ $\beta$-MCD possessing strong quadrupolar amphiphilicity character (ii). The latter pore-system is much more ordered and uniform. (b) Shows the corresponding CLDfunctions calculated from the SAXS curves showing the nano-flat character of the walls (by the low intercept with the Y-axis), the average pore size of the order of the CD-diameter, and the strong alignment of the CD-units in case of the inclusion complexes (by the shape of the tail towards larger sizes).

In addition, a number of fragile transition states and defect structures of self-assembly systems were already caught by nanocasting. Here, quantitative defect analysis allows us to learn about the physics of the assembly process. As a single example, Fig. 13 depicts the structure of the lyotropic phase of an amphiphilic block copolymer close to a structural phase transition from a micellar $\left(\mathrm{L}_{1}\right)$ to a lamellar $\left(\mathrm{L}_{\mathrm{a}}\right)$ phase, but still in the lamellar phase. ${ }^{31}$ Obviously, the system already has adopted some characteristics of the lamellar phase (the micelles are not spherical, but form a foam-like structure) and contains a number of defect structures, such as vesicles or vesicles-filledwith-micelles, which are precisely depicted by nanocasting. This gives very strong indications that lyotropic phase transitions are not strictly first order, as classically assumed.

In a different work transformation of a $\mathrm{L}_{3}$ vesicle-like phase to a porous silica also resulted in very interesting materials. ${ }^{91,92}$

\section{In situ deposition of metal nanoparticles and carbon nanostructures}

Since porous silica is a well known catalytic and chromatographic support material, it was nearby to employ nanocasting in the presence of catalytically active nanoparticles, preferably a)

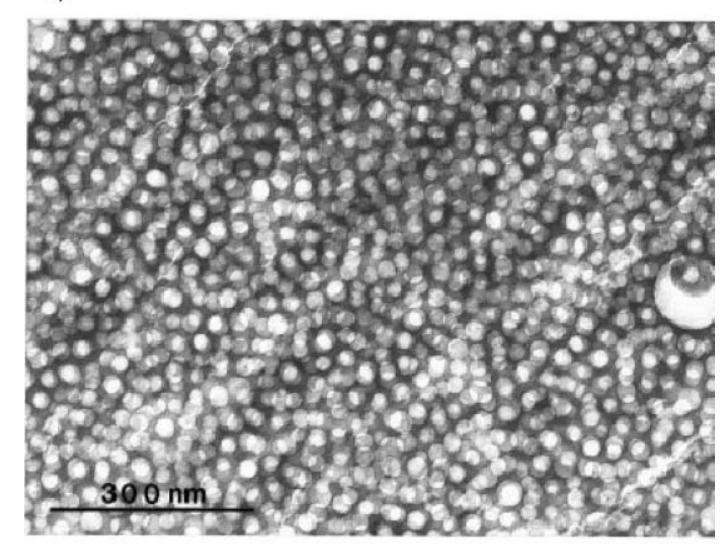

b)

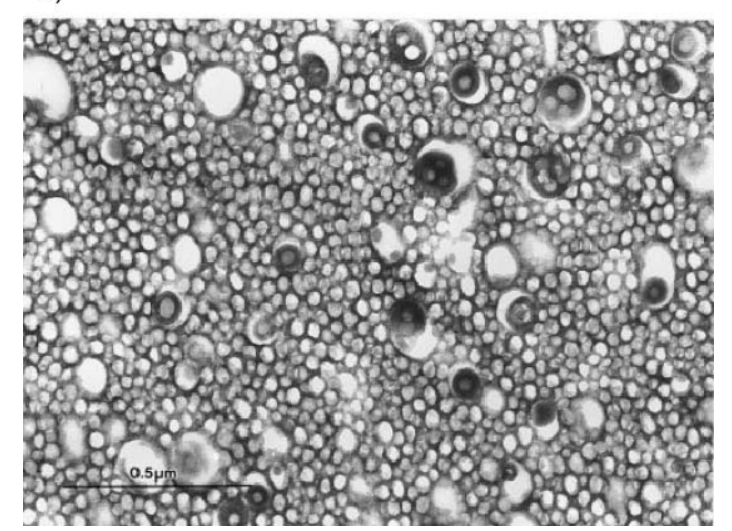

Fig. 13 Nanocasting of the lyotropic phases of two cationic block copolymers, one in the micellar $\mathrm{L}_{1}$-phase the other very close to the $\mathrm{L}_{1} \rightarrow$ $\mathrm{L}_{\mathrm{a}}$ transition towards lamellar structures. Precursor structures (vesicles filled with micelles) as well as an altered wall geometry are found, indicating the partial second order character of this transition.

as a mixture of catalyst and template. Since metal nanoparticles can be made and stabilized within the lyotropic phases of surfactants and amphiphilic block copolymers, in situ nanocasting directly reveals, after calcination, the bare nanoparticles deposited onto the silica walls. ${ }^{74}$ This is nicely shown in Fig. 14 where the structure of the nanoparticles loaded self-assembly structure and the final functionalised silica replica are directly compared with each other.

Further, one can use the ability of cyclodextrins to form inclusion complexes with all sorts of organic complexes, organometallic compounds for instance. By forming inclusion complexes of organometallic complexes with CDs and employing this as a template one obtains silica-metal hybrid materials having a pore system with all the advantages of CD-based pores. ${ }^{88}$ Metal colloids ranging nearly through the whole periodic table with different sizes, controlled by the pore confinement $(1.5-2 \mathrm{~nm})$, or even just permanently fixed and embedded in the wall, can be prepared this way. ${ }^{88}$

This second repetition of casting brings nanocasting to the next step of complexity: The pores themselves act as 'inverse' templates for the production of new materials possessing the same structure as the originally cast template had. In this respect the work of Ryoo et al., who produced new carbon materials by infiltrating the pores of ordered mesoporous materials with carbon precursors followed by carbonization, has to be underlined. ${ }^{93,94}$

Recently, it was pointed out that such carbon-silica nanocomposites are, due to the absence of appropriate IR-radiation bands, superb solar energy absorbers which are easily applicable and environmentally uncritical. ${ }^{95}$ 
a)

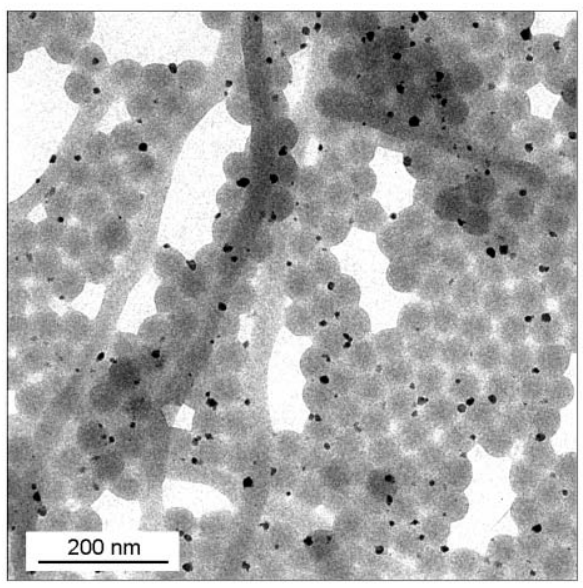

b)

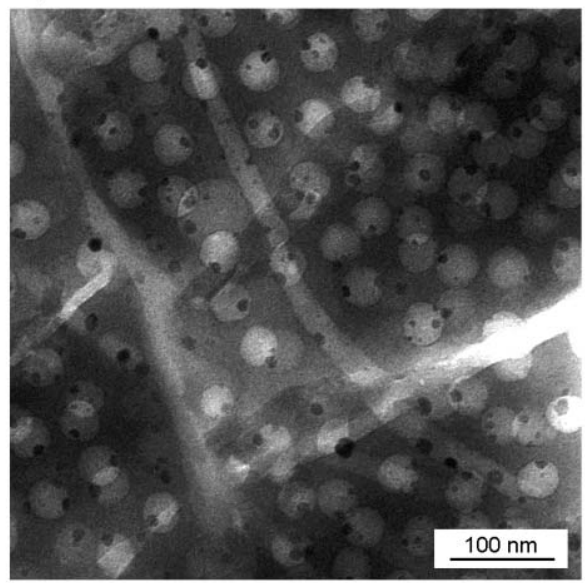

Fig. 14 Nanocasting of a micellar phase of amphiphilic block copolymers loaded with larger Pd-colloids (a), and its silica replica (b). Again, structural preservation as well as directional transfer of the noble metal nanoparticles into the porous structure is easily seen. Both phase structure and particle size were chosen for illustration, but are not optimal for catalysis.

\section{Conclusion and outlook}

In this contribution the nanocasting process, the 3D-transformation of self-assembled organic nanostructures into hollow inorganic replicas under preservation of fine structural details, has been reviewed. It was shown that this technique enables the generation of porous materials, mainly however amorphous silica, in a rather wide pore size range between 1 and $100 \mathrm{~nm}$, partly with Ångstrom control, and variable pore connectivity. The samples are obtained as monoliths or thin films, are very homogeneous, but macroscopically not aligned. The range of templates already applied in nanocasting covers molecules, polymers, supramolecular entities, micelles, lyotropic phases, gels..., with the only prerequisite characterizing a successful template being that its surface has to bind to the matrix material.

Although the systematic exploration of further templates might turn out to be fruitful and will certainly be done, we regard the future of the field to be in exploring the scientific potential of the resulting systems, that is to use them rather than to make more variations.

It was pointed out that one application of nanocasting is learning about soft matter organization: the replication of an ordered supramolecular solution structure, both organic and inorganic, into the silica replica allows its partial structural characterization on the Ångstrom to nanometer scale without the need to produce a large single crystal, as would be necessary in classical crystallography. It is obvious that the bigger and more detailed the solution, the harder its crystallization, but the easier the nanocasting. Therefore, nanocasting might become a complementary technique for the characterization of chemical nanostructures. Two classes where we see direct implementation are larger derivatives with cyclodextrin residues and dynamic libraries of polyoxometalates.

Some promise is also shown in making use of the potential Ångstrom control of pore sizes. It is well known that liquid matter in nanosized confinements show a very special behavior, as it was shown with dynamic relaxation experiments. 96,97 Nanocast silica might act in such experiments as 'nanocuvettes', however with high filling factors and preserving optical transparency, since $c a$. $50 \%$ of the material's volume is accessible and quantum confined.

Also for the synthesis and analysis of nanostructure solids, porous materials should promote some experiments. It was shown that a silica pore is indeed able to confine growth processes of colloids: e.g. a $5.5 \mathrm{~nm}$ colloid can be produced in a $5.5 \mathrm{~nm}$ pore. ${ }^{98}$ This was also used for the preparation of semiconductor nanoparticles, ${ }^{99-102}$ metal colloids or even metal nanowires, ${ }^{103,104}$ or carbon structures. ${ }^{95,105}$ This new field of research where chemistry is done under confinements or with special side conditions (i.e. preservation of size or particle number) is meanwhile known as nanochemistry. ${ }^{82}$ It is not only that a new mode of cluster control is established, it is also that these materials show an altered physicochemical behavior, such as new modes of fluorescence ${ }^{100,101}$ or other 'proximity' effects by a 'nano-mixing' of two otherwise non-compatible systems, fixing the length scales and the mutual interface by the pore architecture. Although those experiments were already done with zeolites and MCMs, nanocast materials might offer the advantage of their monolithic structure (no unspecific outer surface), their large scale homogeneity and their wider variability.

\section{Notes and references}

1 J. Rouqerol, D. Avnir, C. W. Fairbridge, D. H. Everett, J. H. Haynes, N. Pernicone, J. D. Ramsay, K. S. W. Sing and K. K. Unger, Pure Appl. Chem., 1994, 66, 1739-1758.

2 K. S. W. Sing, D. H. Everett, R. A. W. Haul, L. Moscou, R. A. Pierotti, J. Rouquérol and T. Siemieniewska, Pure Appl. Chem., 1985, 57, 603-619.

3 D. W. Breck, W. G. Eversole, R. M. Milton, T. B. Reed and T. L. Thomas, J. Am. Chem. Soc., 1956, 78, 5963-5971.

4 J. Livage, Advanced Zeolite Science and Applications, 1994, 85, $1-42$.

5 J. M. Garces, Adv. Mater., 1996, 8, 434-437.

6 A. K. Cheetham, G. Ferey and T. Loiseau, Angew. Chem., 1999, 111, 3466-3492

7 J. S. Beck, J. C. Vartuli, W. J. Roth, M. E. Leonowicz, C. T. Kresge, K. D. Schmitt, C. T. Chu, D. H. Olson, E. W. Sheppard, S. B. McCullen, J. B. Higgins and J. L. Schlenker, J. Am. Chem. Soc., 1992, 114, 10834-10843.

8 C. T. Kresge, M. Leonowicz, W. J. Roth, J. C. Vartuli and J. S. Beck, Nature, 1992, 359, 710-712.

9 F. DiRenzo, H. Cambon and R. Dutartre, Microp. Mater., 1997, 10, 283-286.

10 U. Ciesla and F. Schüth, Microporous Mesoporous Mater., 1999, 27, 131-149.

11 J. S. Beck and J. C. Vartuli, Curr. Opin. Sol. State. Mat. Sci., 1996, 1, 76-87.

12 J. Y. Ying, C. P. Mehnert and M. S. Wong, Angew. Chem., 1999, 38, $58-82$. 
13 N. Hüsing and U. Schubert, Angew. Chem., 1998, 110, 22-47.

14 A. Sayari, Chem. Mater., 1996, 8, 1840-1852.

15 K. Moller and T. Bein, Chem. Mater., 1998, 10, 2950-2963.

16 A. Stein, B. J. Melde and R. C. Schroden, Adv. Mater., 2000, 12, 1403-1419.

17 G. S. Attard, C. G. Göltner, J. M. Corker, S. Henke and R. H. Templer, Angew. Chem., 1997, 109, 1372-1374.

18 G. S. Attard, J. G. Glyde and C. G. Göltner, Nature, 1995, 378, 366-368.

19 C. G. Göltner, S. Henke, M. C. Weißenberger and M. Antonietti, Angew. Chem., 1998, 110, 633-636.

20 C. G. Göltner and M. Antonietti, Adv. Mater., 1997, 9, 431.

21 C. J. Brinker and G. W. Scherer, Sol-Gel Science: The Physics and Chemistry of Sol-Gel Processing, 1st edn., Academic Press Inc., New York, 1990.

22 F. H. Dickey, Proc. Nat. Acad. Sci., 1949, 35, 227-229.

23 G. D. Stucky and B. F. Chmelka, Science, 1995, 267, 1138-1143.

24 Q. S. Hue, D. I. Margolese, U. Ciesla, P. Y. Feng, T. E. Gier, P. Sieger, R. Leon, . M. Petroff, F. Schuth and G. D. Stucky, Nature, 1994, 368 317-321.

25 A. Monnier, F. Schuth, Q. Huo, D. Kumar, D. Margolese, R. S Maxwell, G. D. Stucky, M. Krishnamurty, P. Petroff, A. Firouzi, M. Janicke and B. F. Chmelka, Science, 1993, 261, 1299-1303.

26 S. A. Bagshaw, E. Prouzet and T. J. Pinnavaia, Science, 1995, 269, 1242-1244.

27 P. T. Tanev and T. J. Pinnavaia, Science, 1995, 267, 865-867.

28 E. Prouzet and T. J. Pinnavaia, Angew. Chem., 1997, 109, 533-536.

29 Y. Wei, J. G. Xu, H. Dong, J. H. Dong, K. Y. Qiu and S. A. JansenVarnum, Chem. Mater., 1999, 11, 2023-2029.

30 P. Behrens, personal communication.

31 E. Krämer, S. Förster, C. Göltner and M. Antonietti, Langmuir, 1998 , 14, 2027-2031.

32 M. Breulmann, S. A. Davis, S. Mann, H. P. Hentze and M. Antonietti, Adv. Mater., 2000, 12, 502-507.

33 D. Grosso, G. Soler-Illia, F. Babonneau, C. Sanchez, P. A. Albouy, A Brunet-Bruneau and A. R. Balkenende, Adv. Mater., 2001, 13, 1085-1090.

34 P. Yang, D. Zhao, D. I. Margolese, B. F. Chmelka and G. D. Stucky, Nature, 2000, 396, 152-155.

35 J. M. Elliot, P. R. Birkin, P. N. Bartlett and G. S. Attard, Langmuir, 1999, 15, 7411-7415.

36 R. A. Caruso, M. Giersing, F. Willing and M. Antonietti, Langmuir, 1998, 14, 6333-6336.

37 R. A. Caruso, J. H. Schattka and A. Greiner, Adv. Mater., 2001, 13, 1577-1579.

38 R. A. Caruso and M. Antonietti, Chem. Mater., 2001, 13, 3272-3282.

39 E. L. Crepaldi, G. Soler-Illia, D. Grosso, P. A. Albouy and C. Sanchez, Chem. Commun., 2001, 1582-1583.

40 A. Bouchara, G. Soler-Illia, J. Y. Chane-Ching and C. Sanchez, Chem. Commun., 2002, 1234-1235.

41 G. Soler-Illia, A. Louis and C. Sanchez, Chem. Mater., 2002, 14, $750-759$.

42 H. P. Hentze and M. Antonietti, Curr. Opin. Solid State Mater. Sci., 2001, 5, 343-353.

43 M. A. Hillmyer, P. M. Lipic, D. A. Hajduk, K. Almdal and F. S. Bates, J. Am. Chem. Soc., 1997, 119, 2749-2750.

44 P. T. Tanev and T. J. Pinnavaia, Chem. Mater., 1996, 8, 2068-2079.

45 K. W. Sing, Adv. Colloid Interf. Sci., 1998, 76-77, 3-11.

46 S. J. Gregg and K. S. W. Sing, Adsorption, Surface Area and Porosity, 4th edn., Academic Press, 1982.

47 G. S. Attard, M. Edgar and C. G. Goltner, Acta Mater., 1998, 46, 751-758.

48 M. Edgar, M. Schubert, H. H. Limbach and C. G. Goltner, Ber. Bunsen-Ges. Phys.Chem. Chem. Phys., 1997, 101, 1769-1772.

49 D. Y. Zhao, J. Y.; Sun, Q. Z. Li and G. D. Stucky, Chem. Mater., 2000, 12, 275-279.

50 Y. Sakamoto, M. Kaneda, O. Terasaki, D. Y. Zhao, J. M. Kim, G. D. Stucky, H. J. Shin and R. Ryoo, Nature, 2000, 408, 449-453.

51 C. Göltner, B. Smarsly, B. Berton and M. Antonietti, Chem. Mater., 2001, 13, 1617-1624.

52 B. Smarsly, C. Goltner, M. Antonietti, W. Ruland and E. Hoinkis, $J$. Phys. Chem. B, 2001, 105, 831-840.
53 B. Smarsly, M. Antoniett and T. Wolff, J. Chem. Phys., 2002, 116, 2618-2627.

54 J. P. Olivier, Carbon, 1998, 36, 1469-1472.

55 P. I. Ravikovitch, G. L. Haller and A. V. Neimark, Adv. Colloid Interf. Sci., 1998, 76-77, 203-226.

56 B. Smarsly, S. Polarz and M. Antonietti, J. Phys. Chem. B, 2001, 105, 10473-10483.

57 S. Kim, T. R. Pauly and T. J. Pinnavaia, Chem. Commun., 2000, 1661-1662.

58 H. P. Hentze, E. Krämer, B. Berton, S. Förster and M. Antonietti, Macromolecules, 1999, 32, 5803-5809.

59 C. G. Göltner, B. Berton, E. Krämer and M. Antonietti, Adv. Mater., 1999, 11, 395-398.

60 D. Zhao, Q. Huo, J. Feng, B. F. Chmelka and G. D. Stucky, J. Am. Chem. Soc., 1998, 120, 6024-6036.

61 D. Zhao, J. Feng, Q. Huo, N. Melosh, G. H. Fredrickson, B. F. Chmelka and G. D. Stucky, Science, 1998, 279, 548-552.

62 C. G. Goltner, B. Berton, E. Kramer and M. Antonietti, Adv. Mater., 1999, 11, 395-398.

63 C. G. Göltner, B. Berton, E. Krämer and M. Antonietti, Chem. Commun., 1998, 2287-2288.

64 S. Forster, B. Berton, H. P. Hentze, E. Kramer, M. Antonietti and P. Lindner, Macromolecules, 2001, 34, 4610-4623.

65 K. Mosbach, Trends Biochem. Sci., 1994, 19, 9-14.

66 J. Matsui, T. Kato, T. Takeuchi, M. Suzuki, K. Yokoyama, E. Tamiya and I. Karube, Anal. Chem., 1993, 65, 2223-2224.

67 C. G. Göltner, B. Smarsly, B. Berton and M. Antonietti, Chem. Mater., 2001, 13, 1617-1624.

68 S. Polarz, Silica Organic Hybrid Materials, American Scientific Publishers, Stevenson Ranch, CA, 2002.

69 E. J. A. Pope, M. Assami and J. D. MacKenzie, J. Mater. Res., 1989 4, 1018-1026.

70 T. Hino, K. Mochida and S. Okumara, Kobunshi Ronbunshu, 1983, 40, 225-233.

71 T. Saegusa, J. Macromol. Sci. Chem. A, 1991, 28, 817-829.

72 G. Larsen and E. Lotero, J. Phys. Chem. B, 2000, 104, 4840-4843.

73 M. Antonietti, B. Berton, C. Göltner and H. P. Hentze, Adv. Mater., 1998, 10, 154-159.

74 N. T. Whilton, B. Berton, L. Bronstein, H. P. Hentze and M. Antonietti, Adv. Mater., 1999, 11, 1014-1018.

75 B. T. Holland, C. F. Blanford, T. Do and A. Stein, Chem. Mater., 1999, 11, 795-805.

76 J. Wijnhoven and W. L. Vos, Science, 1998, 281, 802-804.

77 A. Stein, Microporous Mesoporous Mater., 2001, 44, 227-239.

78 A. Müller, S. Polarz, S. K. Das, E. Krickemeyer, H. Bogge, M. Schmidtmann and B. Hauptfleisch, Angew. Chem., Int. Ed., 1999, 38 3241-3245.

79 A. Müller, E. Krickemeyer, H. Bögge, M. Schmidtmann and F. Peters, Angew. Chem., 1998, 110, 3567-3571.

80 S. Polarz, B. Smarsly, C. Göltner and M. Antonietti, Adv. Mater., 2000, 12, 1503-1507.

81 M. S. Morey, J. D. Bryan, S. Schwarz and G. D. Stucky, Chem. Mater. 2000, 12, 3435-3444.

82 G. A. Ozin, Adv. Mater., 1992, 4, 612

83 M. Antonietti, K. Landfester and Y. Mastai, Isr. J. Chem., 2001, 41, $1-5$.

84 S. Polarz, B. Smarsly, L. Bronstein and M. Antonietti, Angew. Chem., Int. Ed., 2001, 40, 4417-4421.

85 W. Saenger, Angew. Chem., Int. Ed. Engl., 1980, 19, 344-362.

86 O. Häusler and C. C. Müller-Goymann, Starch, 1993, 45, 183-187.

87 A. W. Coleman, I. Nicolis, N. Keller and J. P. Dalbiez, J. Inclusion Phenom. Mol. Recognit. Chem., 1992, 13, 139-143.

88 B. H. Han, S. Polarz and M. Antonietti, Chem. Mater., 2001, 13, 3915-3919.

89 B.-H. Han and M. Antonietti, Chem. Mater., 2002, 14, 3477-3485.

90 M. Antonietti, H. P. Hentze, B. Smarsly, M. Loffler and R. Morschhauser, Macromol. Mater. Eng., 2002, 287, 195-202.

91 K. M. McGrath, D. M. Dabbs, N. Yao, I. A. Aksay and S. M. Gruner, Science, 1997, 277, 552-556.

92 K. M. McGrath, D. M. ; Dabbs, N. Yao, K. J. Edler, I. A. Aksay and S. M. Gruner, Langmuir, 2000, 16, 398-406.

93 R. Ryoo, S. H. Joo, M. Kruk and M. Jaroniec, Adv. Mater., 2001, 13, 677-681. 
94 R. Ryoo, S. H. Joo and S. Jun, J. Phys. Chem. B, 1999, 103, 7743-7746.

95 Y. Mastai, S. Polarz and M. Antonietti, Adv. Funct. Mater., 2002, 12, 197.

96 A. Huwe, M. Arndt, F. Kremer, C. Haggenmulle and P. Behrens, J. Chem. Phys., 1997, 107, 9699-9701.

97 M. Schoen, M. Thommes and G. H. Findenegg, J. Chem. Phys., 1997, 107, 3262-3266.

98 L. M. Bronstein, S. Polarz, B. Smarsly and M. Antonietti, Adv. Mater., 2001, 13, 1333-1336.

99 H. Winkler, A. Birkner, V. Hagen, I. Wolf, R. Schmechel, H. v. Seggern and R. A. Fischer, Adv. Mater., 1999, 11, 1444-1448.
100 O. Dag, G. A. Ozin, H. Yang, C. Reber and G. Bussiere, Adv. Mater., 1999, 11, 474-480.

101 E. Chomski, O. Dag, A. Kuperman, N. Coombs and G. A. Ozin, Chem. Vap. Deposition, 1996, 2, 8-00.

102 R. Leon, D. Margolese, G. Stucky and P. M. Petroff, Physical Review $B, 1995$, 52, R2285-R2288.

103 H. Kang, Y. Jun, J. Park, K. Lee and J. Cheon, Chem. Mater., 2000, 12 , 3530-3532.

104 J. Han, J. M. Kim and G. D. Stucky, Chem. Mater., 2000, 12, 2068-2069.

105 C. Wu and T. Bein, Science, 1994, 266, 1013-1014. 